Voix et Images

voixetimages

\title{
Hubert Aquin et le Théâtre au XIX
}

\section{Jacques Michon}

Volume 7, numéro 2, hiver 1982

Michel Tremblay

URI : https://id.erudit.org/iderudit/200330ar

DOI : https://doi.org/10.7202/200330ar

Aller au sommaire du numéro

\section{Éditeur(s)}

Les Presses de l'Université du Québec

\section{ISSN}

0318-9201 (imprimé)

1705-933X (numérique)

Découvrir la revue

\section{Citer cet article}

Michon, J. (1982). Hubert Aquin et le Théâtre au XIX ${ }^{\mathrm{e}}$. Voix et Images, 7(2), 405-407. https://doi.org/10.7202/200330ar d'utilisation que vous pouvez consulter en ligne.

https://apropos.erudit.org/fr/usagers/politique-dutilisation/ 


\section{Essais}

\section{Hubert Aquin et le Théâtre au XIXe par Jacques Michon}

LAPIERRE, René, L'Imaginaire captif, Montreal, Quinze, coll. “prose exacte ", 1981, $183 \mathrm{p}$.

On se rend compte après coup que l'œuvre d'Aquin obéissait à une "logique de la dégradation". De Prochain épisode à Neige noire une même impuissance à ouvrir le texte romanesque, à donner accès aux pouvoirs de l'imaginaire, aux possibles narratifs s'affirmerait, s'approfondirait, s'aggraverait jusqu'au silence d'Obombre. La captivité scripturaire, la lente paralysie de l'imaginaire aquinien, déjà en germe dans les hésitations et les atermoiements du narrateur de Prochain épisode se confirmeraient de façon décisive dans l'Antiphonaire, "une œuvre limite, dressée dans un équilibre périlleux sur le seuil de sa disparition» (p. 115). Par rapport à cette limite, Neige noire ne serait que le résidu de la crise inéluctable, irréversible.

Lapierre retrace de roman en roman le sens qui semble dominer ce texte miné de l'intérieur par une force obscure, dévoré par son propre dynamisme, œuvre en quelque sorte implosée. Quelle est cette «expérience de langage que tout, depuis Prochain épisode, destinait à se refermer sur elle-même" (p. 149), qui aboutit au démembrement, à la "déroute élocutoire", à la "détérioration" sans retour?

Alors que l'œuvre d'Aquin semble présenter toutes les apparences du texte moderne, dominé par l'éclatement polyphonique ou polysémique, alors qu'elle semble jouer des figures narratives de la modernité, elle serait en fait tout au contraire figée dans la posture d'un texte classique, terroriste, refermée sur une illusion référentielle, rivée à la chose (passé, vécu) qu'elle voudrait reproduire, arrêter, fixer. Aquin serait fasciné par ce qui détruirait les possibilités mêmes de l'ouverture ou de l'épanouissement de l'imaginaire romanesque. L'imaginaire aquinien serait captif du réel. Cette "faille originelle" bloquerait toute progression de l'œuvre, l'inversant, la destinant a involuer dramatiquement vers sa disparition élocutoire. L'œuvre d'Aquin ne serait pas assez décollée de la réalité, päs assez jouée, œuvrée, ouverte. II n'y aurait pas ici comme chez les grands romanciers 
de la modernité, cette distance métalinguistique qui permet le jeu libre de l'imagination et du sens.

Les noms de Borgès et Cortazar reviennent souvent sous la plume de Lapierre pour désigner le récit moderne, ludique, ouvert. La lisibilité de ces textes repose, comme on sait, sur un fond de discours classique. Si ces œuvres produisent des effets d'ouverture c'est à partir du code réaliste légitimé qu'il mine tout en le mimant. Le lecteur ici a toujours été initialement placé en position de vraisemblance, c'est à partir de là, après un conditionnement plus ou moins prolongé, qu'il verra ses codes ébranlés, basculer, vaciller à la faveur de figures savamment orchestrées (métalepse, mise en abyme). Chez Aquin nul compromis de départ avec la tradition, nous sommes d'emblée, dès les premiers mots du roman, plongés dans un univers «abymé", sans fond, qui a déjà basculé. Le narrateur d'Aquin regarde les codes de la réalité (Balzac, Holbein) par en dessous, comme un idéal à atteindre, alors qu'il se trouve pris dans le jeu des analogies verticales. Sa quête est dès lors l'inverse de celle des modernes. Au lieu d'ouvrir le texte traditionnel, de le déconstruire lentement, patiemment, savamment, à partir d'une position de maîtrise, Aquin tente au contraire de se donner un socle, une assise, une légitimité symbolique, de trouver un fondement à ce qui le traverse, en s'appuyant entre autres sur les grandes œuvres de la tradition occidentale. Si le narrateur aquinien est captif de ces chefs-d'œuvre indépassables, il n'en continue pas moins d'afficher, d'étaler tous ces langages qui le traversent, le divisent, le dérivent et le situent dans l'aléatoire, l'indéterminé d'une écriture rapsodique, paradigmatique, qui n'arrive pas à se narrativiser. C'est cette complémentarité de la dérive verticale, vertigineuse et du roman impossible qui semble caractériser l'écriture d'Aquin et la situer à sa façon dans la modernité et non à côté ou à rebours comme semble l'indiquer la thèse de Lapierre.

LARRUE, Jean-Marc, Le Théâtre à Montréal à la fin du XIXE siècle, Monttréal, Fides, 1981, $139 \mathrm{p}$.

Nous savions que le theâtre à Montréal au tournant du siècle était largement dominé par les troupes et les répertoires étrangers. les mémoires d'Édouard Montpetit, de Victor Barbeau et le livre de Marcel Dugas sur le Théâtre à Montréal (1911) nous avaient fait connaître le goût du public lettré de la "belle époque" pour le drame historique et le vaudeville. Mais nous ne savions pas dans quelle mesure, dans quelle proportion ces témoignages reflétaient la réalité théâtrale. Jean-Marc Larrue dans une petite étude sur le théâtre à Montréal de 1890 à 1900 nous donne un aperçu objectif et chiffré de cette réalité. Avec force statistiques et tableaux, il nous montre quelle était l'importance du théâtre francophone comparée à celle 
du théâtre anglophone, quels genres de pièces (drames, comédies, vaudevilles, opéras, opérettes) avaient la faveur du public et quels étaient les spectacles, les troupes et les vedettes les plus populaires.

Larrue semble avoir dépouillé systématiquement toute la presse quotidienne de cette période. Il a obtenu ainsi des chiffres impressionnants quant au nombre de titres mis à l'affiche (1899) et au nombre de représentations (11 321) données durant la décennie. Ce sont les pièces anglophones (1 395 titres) et françaises (477 titres) qui se taillent ici la part du lion. Par comparaison la production canadienne-française avec 17 titres demeure négligeable, d'autant plus que parmi celle-ci Larrue compte également les "adaptations d'œuvres françaises", ce qui réduit encore l'apport autochtone.

Dans cette catégorie des pièces françaises adaptées, Larrue classe le drame historique de Paul Kauvar qui aurait été mis au gout canadien par J.H.D. (ou J.A.D.?) Tougas en 1898, alors que cette pièce était une œuvre dramatique américaine de James Steale Mackay créée en 1887. Jouée à Montréal en anglais à plusieurs reprises entre 1889 et 1894 , cette pièce avait été montée en français (déjà dans la version de Tougas) en 1895 , donc avant 1898, comme on peut le lire dans un compte rendu paru dans l'Écho des jeunes de cette année-là. Ces faits n'auraient probablement pas échappé à Larrue s'il avait étendu son enquête aux revues ou s'il avait eu une connaissance plus complète du champ littéraire de cette époque. En effet ne sait-on pas depuis l'étude de P. Wyczynski sur Émile Nelligan, sources et originalité de son œuvre (1960) que la pièce de Mackay avait eu beaucoup de succès au début des années 1890, au point d'inspirer à Nelligan son premier pseudonyme (Émile Kovar)?

On touche ici aux limites de ce travail où l'auteur s'est imposé un cadre étroit qui ne dépasse pas les niveaux de l'inventaire statistique et du compte rendu de presse. On le remerciera par contre d'avoir ouvert un dossier particulièrement riche et d'avoir ajouté un index à son petit ouvrage, ce qui en facilitera la consultation et sera utile à celui qui voudra poursuivre l'enquête, la compléter ou en reprendre les données pour les interpréter. 